\title{
Dentate Gyrus Contributes to Retrieval as well as Encoding: Evidence from Context Fear Conditioning, Recall, and Extinction
}

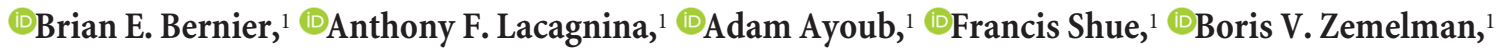 \\ Franklin B. Krasne, ${ }^{2}$ and Michael R. Drew ${ }^{1}$ \\ ${ }^{1}$ Center for Learning and Memory, Department of Neuroscience, University of Texas at Austin, Austin, Texas 78712, and ${ }^{2}$ Department of Psychology, \\ University of California at Los Angeles, Los Angeles, California 90095
}

Dentate gyrus (DG) is widely thought to provide a teaching signal that enables hippocampal encoding of memories, but its role during retrieval is poorly understood. Some data and models suggest that DG plays no role in retrieval; others encourage the opposite conclusion. To resolve this controversy, we evaluated the effects of optogenetic inhibition of dorsal DG during context fear conditioning, recall, generalization, and extinction in male mice. We found that (1) inhibition during training impaired context fear acquisition; (2) inhibition during recall did not impair fear expression in the training context, unless mice had to distinguish between similar feared and neutral contexts; (3) inhibition increased generalization of fear to an unfamiliar context that was similar to a feared one and impaired fear expression in the conditioned context when it was similar to a neutral one; and (4) inhibition impaired fear extinction. These effects, as well as several seemingly contradictory published findings, could be reproduced by BACON (Bayesian Context Fear Algorithm), a physiologically realistic hippocampal model positing that acquisition and retrieval both involve coordinated activity in DG and CA3. Our findings thus suggest that DG contributes to retrieval and extinction, as well as to the initial establishment of context fear.

Key words: context; dentate gyrus; extinction; fear conditioning; hippocampus; memory

\section{Significance Statement}

Despite abundant evidence that the hippocampal dentate gyrus (DG) plays a critical role in memory, it remains unclear whether the role of DG relates to memory acquisition or retrieval. Using contextual fear conditioning and optogenetic inhibition, we show that DG contributes to both of these processes. Using computational simulations, we identify specific mechanisms through which the suppression of DG affects memory performance. Finally, we show that DG contributes to fear extinction learning, a process in which learned fear is attenuated through exposures to a fearful context in the absence of threat. Our data resolve a long-standing question about the role of DG in memory and provide insight into how disorders affecting DG, including aging, stress, and depression, influence cognitive processes.

\section{Introduction}

The hippocampal dentate gyrus (DG) has emerged as a critical locus of plasticity with relevance to memory, anxiety disorders, and depression. Manipulations targeted specifically to DG impair

Received Sept. 28, 2016; revised April 10, 2017; accepted May 20, 2017.

Author contributions: B.E.B., F.B.K., and M.R.D. designed research; B.E.B., A.F.L., A.A., F.S., and F.B.K. performed research; B.V.Z. contributed unpublished reagents/analytic tools; B.E.B., A.F.L., F.B.K., and M.R.D. analyzed data; B.E.B., F.B.K., and M.R.D. wrote the paper.

This work was supported by National Institutes of Health Grants R01MH102595 and ROOMH083943 to M.R.D.; R21 EY026446 to B.V.Z. and M.R.D.; R01 MH062122 to M.S. Fanselow and F.B.K.; Human Frontiers Science Program GrantHFSP RGP0041 to B.V.Z.;NIH F31MH111243 and T32MH106454 to A.F.L.; and UT Brain Grant UTS-NNRI 365289 to B.V.Z. and M.R.D. We thank Dr. Michael D. Mauk for thoughtful discussion and suggestions on this manuscript. We thank Drs. Raymond A. Chitwood and Jared B. Bowden for guidance on field potential recordings. We thank Hee Ju Kim, Jennifer Tribble, Alexa Hassien, and Taylor Copeland for assistance with surgery and histology.

The authors declare no competing financial interests. memory acquisition (Kheirbek et al., 2013; Madroñal et al., 2016), modulate anxiety levels (Snyder et al., 2011; Samuels et al., 2015; Seo et al., 2015), and block some effects of antidepressant drugs in clinically relevant models (Santarelli et al., 2003; David et al., 2009), leading to speculation that DG is a promising target for therapeutic manipulations (Drew and Hen, 2007; Kheirbek et al., 2012).

The DG is thought to perform pattern separation, the decorrelation of neural inputs to the hippocampus (O'Reilly and McClelland, 1994; Treves and Rolls, 1994; Rolls, 1996). Manipulations that im-

Correspondence should be addressed to Dr. Michael R. Drew, Center for Learning and Memory, University of Texas at Austin, 1 University Station C7000, Austin, TX 78712. E-mail:mdrew@utexas.edu.

DOI:10.1523/JNEUROSCI.3029-16.2017

Copyright $\odot 2017$ the authors $\quad 0270-6474 / 17 / 376359-13 \$ 15.00 / 0$ 
pair DG pattern separation during encoding are hypothesized to lead to increased interference in CA3 during retrieval, thereby impairing memory precision and discrimination learning (McHugh et al., 2007; Sahay et al., 2011; Nakashiba et al., 2012; Swan et al., 2014). When memory is of an aversive nature, impaired pattern separation may lead to generalized fear and anxiety and form the seed of anxiety disorders (Kheirbek et al., 2012; Phan et al., 2013; Drew and Huckleberry, 2017).

DG pattern separation is widely believed to be critical during hippocampal memory acquisition, but its contribution to memory retrieval is debated. Some theoretical accounts (Rolls, 1996; Rolls and Kesner, 2006) propose that sparse patterns of activation in DG enable memory encoding in CA3, whereas memory retrieval is mediated through direct cortical inputs to CA3. This account is supported by a number of studies showing that suppressing or lesioning the DG interferes with memory acquisition but not with the expression of already learned memories (Lassalle et al., 2000; Kheirbek et al., 2013; Madroñal et al., 2016). However, other theoretical accounts conclude that DG contributes to both memory acquisition and retrieval (O'Reilly and McClelland, 1994; Krasne et al., 2015), a prediction supported by recording studies (Leutgeb et al., 2007) and studies using activitydependent neural tagging (Deng et al., 2013; Denny et al., 2014) that have shown that memory acquisition and expression activate similar populations of DG neurons. In addition, optogenetic stimulation of DG neurons that had been activated during fear memory acquisition drives fear expression (Liu et al., 2012; Ramirez et al., 2013; Redondo et al., 2014; Ryan et al., 2015), whereas suppressing these cells attenuates fear expression (Denny et al., 2014). The literature thus contains a paradox: on the one hand, activating granule cell ensembles genetically tagged during acquisition is sufficient to drive memory recall, and silencing these ensembles can prevent it; on the other hand, more comprehensive silencing of DG does not reliably prevent memory expression.

We used transient optogenetic suppression of dorsal DG to investigate its role in individual memory stages during contextual fear conditioning (CFC). Context fear conditioning provides a useful window into hippocampal function because the hippocampus plays a critical role in forming and retrieving neural representations of the context to which fear becomes conditioned (Rudy et al., 2004; Fanselow, 2010). In addition to examining the acquisition and expression of context fear, we studied the role of DG in fear extinction, a process that requires both the retrieval of hippocampally stored information and the acquisition of new learning that may be hippocampal, at least in part (see Discussion). Our data suggest that DG plays a role in both fear acquisition and extinction. Expression of fear or extinction memories did not require DG. However, the suppression of DG neural activity during fear expression impaired the ability to distinguish between similar contexts, leading to apparent overgeneralization of both fear and neutral memories. Simulations using a biologically realistic computational model of the hippocampus that formalizes common views of the role of hippocampus in context fear learning suggest that our findings, as well as apparently conflicting published findings, are all consistent with the hypothesis that both acquisition and retrieval involve coordinated activity in DG and CA3.

\section{Materials and Methods}

Subjects. Male C57BL/6J mice obtained from The Jackson Laboratory (RRID:IMSR_JAX:000664) were housed in groups of four in plastic cages with wood chip bedding and were maintained on a $12 \mathrm{~h}$ light/dark cycle
(7:00 A.M. to 7:00 P.M.) in a temperature- and humidity-controlled vivarium. Food and water were provided ad libitum. Experiments were conducted during the light phase. All procedures were approved by the University of Texas at Austin Institutional Animal Care and Use Committee.

Stereotaxic surgery. Mice underwent stereotaxic surgery for virus injection at $8-10$ weeks of age. Viruses ( $\mathrm{rAAV} 2 / 7$, rep/cap) expressing eNpHR3.0-sfGFP fusion protein (Royer et al., 2012) or eGFP under the human synapsin promoter were assembled using a helper-free system (Stratagene) and were purified on sequential cesium gradients according to published methods (Grieger et al., 2006). Titers were measured using a payload-independent quantitative PCR technique (Aurnhammer et al., 2012). Typical titers were $>10^{10}$ genomes/ $\mu$ l. Viruses were injected bilaterally using a NanoJect II microinjector (Drummond) targeted to two locations within the dorsal DG (from bregma: $\mathrm{AP}=-2.0 \mathrm{~mm}$; $\mathrm{ML}=$ $\pm 1.3 \mathrm{~mm} ; \mathrm{DV}=-2.1$ and $1.85 \mathrm{~mm}$ ). At each location, there were two infusions of $23 \mathrm{nl}$ each. The infusions were $1 \mathrm{~s}$ in duration and spaced 1 min apart. Mice were bilaterally implanted with optic fibers during the same surgery at a $20^{\circ}$ angle targeted above the dorsal DG (from bregma: $\mathrm{AP}=-2.0 \mathrm{~mm} ; \mathrm{ML}= \pm 1.3 \mathrm{~mm} ; \mathrm{DV}=-1.5 \mathrm{~mm}$ ). Optic fiber implants were constructed based on published protocols (Sparta et al., 2011), using $1.25 \mathrm{~mm}$ ceramic ferrules (Kientec Systems) and $200 \mu \mathrm{m}$ core, 0.39 numerical aperture multimode fiber (ThorLabs).

Electrophysiology. Mice were anesthetized with isoflurane and placed in a stereotaxic frame. A single-wire tungsten microelectrode $(127 \mu \mathrm{m}$ diameter, $0.5 \mathrm{M} \Omega$; A-M Systems) was lowered into the dentate gyrus (from bregma: AP, $-2.0 \mathrm{~mm}$; ML, $\pm 1.3 \mathrm{~mm}$; DV, $-1.85 \mathrm{~mm}$ ). An identical microelectrode was placed in the ipsilateral angular bundle for perforant path stimulation (from bregma: $\mathrm{AP}=$ lambda; $\mathrm{ML}=2.6$ to 3.0 $\mathrm{mm}$; $\mathrm{DV}=-2.0$ to $-2.25 \mathrm{~mm}$ ). Stimulation was applied using a constant current stimulus isolator (NL800, Digitimer), and the final position of both electrodes was adjusted to maximize positive response. Inputoutput relations were constructed by delivering a series of $100.1-\mathrm{ms}$ duration waveforms with a $500 \mathrm{~ms}$ interstimulus interval beginning at an intensity of $200 \mu \mathrm{A}$ and increasing at $200 \mu \mathrm{A}$ intervals. Each inputoutput current series was repeated three times at each time point and averaged for analysis. At the end of the recording, an electrolytic lesion was made through the recording electrode to allow for verification of the recording site. A model $17 \mathrm{fc} 00$ Differential AC Amplifier (A-M Systems) and AxoGraphX software (Axograph Scientific; RRID:SCR_014284) were used to record and collect data. Responses were analyzed using AxoGraphX software.

Optogenetic inhibition. Experiments occurred 2-3 weeks following virus injection/fiber implantation. Before the start of experiments, mice were handled for 3-4 d; during this time they were habituated to the fiber-optic cables by allowing them to explore a novel cage while tethered to the cables.

For light stimulation, cranial implants were connected to a $140 \mathrm{~mW}$, $532 \mathrm{~nm}$ laser (Shanghai Dream Lasers Technology) via patch cables connected to an FC/PC rotary joint (Doric Lenses). Following cable connection, mice were immediately placed in the behavioral apparatus. Laser intensity was set to output 7-9 $\mathrm{mW}$ at the end of the optic fiber implant.

Novel environment exploration. Novel environment exposure was performed in four gray open field arenas $(40 \times 40 \mathrm{~cm})$ with opaque walls. The arenas were lighted with white incandescent bulbs (65 lux at the center of the arena). Mice were brought to an isolated holding area the day before the start of the experiment to reduce induction of immediateearly genes (IEGs) related to transport and activity in the vivarium. Mice were transported directly from the holding area to the testing room, where they were connected to fiber-optic patch cables and were immediately placed into a novel open field apparatus for $15 \mathrm{~min}$, after which they were returned to their home cage. Ninety minutes later, mice were transcardially perfused and the brains were dissected and prepared for sectioning.

Fear conditioning. Mice were transported to a holding area adjacent to the testing room at least $1 \mathrm{~h}$ before start of experiments. Mice were transported into the testing room in opaque plastic containers. Conditioning always took place in a $30.5 \times 24 \times 21 \mathrm{~cm}$ chamber (Med Associates) with three aluminum walls, a clear Plexiglas door, and ceiling and 
stainless steel grid flooring (Med-Associates VFC-005A; Context A). Conditioning chambers were contained within larger sound-attenuating chambers that were equipped with an overhead white light that was kept on throughout sessions. The apparatus was cleaned before and after each animal with $70 \%$ ethanol and scented with $1 \%$ acetic acid solution in the waste tray below the floor. The similar context (Context C) consisted of the same chamber with a staggered grid flooring (Med-Associates VFC005A-S) cleaned with Lysol cleaning wipes. A one-shock conditioning protocol was used based on evidence that it is more sensitive to hippocampal manipulations than are multiple-shock protocols (Wiltgen et al., 2006; Drew et al., 2010). Mice were connected to fiber-optic patch cables and immediately placed into the apparatus where they received a single $2 \mathrm{~s} 0.75 \mathrm{~mA}$ scrambled footshock delivered through the grid flooring. The shock was delivered $180 \mathrm{~s}$ after the mouse was placed in the chamber; the mouse was removed $30 \mathrm{~s}$ after the shock. For extinction training/context tests mice were returned to the chamber for $5 \mathrm{~min}$ with no shock once per day, a protocol that has previously been demonstrated to produce effective extinction (Bernier et al., 2014). For acquisition and recall experiments, context tests were limited to 3 min to minimize extinction. For the experiment involving pre-exposure to the similar context, the pre-exposure consisted of a 5 min session in the similar context with no shock. Conditioning took place in Context $\mathrm{A}$, as described above, $24 \mathrm{~h}$ after the pre-exposure session. Sessions were recorded with a nearinfrared camera mounted to the door of the sound-attenuating chamber. Freezing was manually scored from the videos by an investigator who was blind to experimental conditions.

Immunohistochemistry. Mice were anesthetized with ketamine/xylazine $(150 / 15 \mathrm{mg} / \mathrm{kg})$ and perfused transcardially with $20-25 \mathrm{ml}$ of cold 0.1 м PBS followed by $15-20 \mathrm{ml}$ of cold $4 \%$ paraformaldehyde (PFA). Brains were then postfixed in 4\% PFA for $24 \mathrm{~h}$ and transferred to a solution of $30 \%$ sucrose in PBS at $4^{\circ} \mathrm{C}$ for cryopreservation. Coronal sections $(35 \mu \mathrm{m})$ were cut on a cryostat and stored in $0.1 \%$ sodium azide in PBS.

For immunostaining, sections were washed in PBS and blocked for $1 \mathrm{~h}$ at room temperature (RT) in $10 \%$ normal donkey serum with $0.1 \%$ Triton X-100 in PBS. Sections were incubated with primary antibody (1:2000; rabbit anti-Arc, Synaptic Systems; RRID:AB_887694) in blocking solution at RT overnight. The following day, sections were washed in PBS and incubated with a secondary antibody (1:500; Cy-3-conjugated donkey anti-rabbit, Jackson ImmunoResearch; RRID:AB_2307443) and 4',6'-diamidino-2-phenylindole dihydrochloride (DAPI; 1:1000; Invitrogen; RRID:AB_2307445) in blocking solution for $1 \mathrm{~h}$ at RT.

Arc quantification. Using DAPI to identify the granule cell layer, $\mathrm{Arc}^{+}$ cells in both the upper and lower blades of the DG were counted exhaustively under fluorescent illumination. Cells were counted in every sixth section (total of 12 sections/animal) across the dorsoventral axis of the hippocampus. Area measurements for calculating density were obtained by tracing the granule cell layer using ImageJ software [National Institutes of Health (https://imagej.nih.gov/ij/; RRID:SCR_003070)].

Simulations. Simulations were performed using BACON (Bayesian Context Fear Algorithm; Krasne et al., 2015). BACON mimics current conceptions of entorhinal cortex (EC), DG, and CA3 circuit operation during context fear conditioning and recall, but it adds nonhippocampal (presumptively prefrontal) circuitry that configures the hippocampus specifically for encoding of a new hippocampal representation or retrieval of an existing one, as appropriate, with the decision on whether to retrieve or encode being based on a comparison between an EC coding of the currently observed attributes of a context and an EC coding of recalled attributes associated with the currently active representation. If these do not match, the hippocampus is configured to create (encode) a new representation of the current context. When in encoding mode, a K-winners-take-all (KWTA) mechanism in DG allows only a small number $\left(\mathrm{K}_{\mathrm{DG}}\right)$ of DG cells most heavily innervated by the currently active cortical representation of the context to fire. Each DG cell that fires then develops effective innervation of a permanent CA3 partner, which becomes one cell of the now-permanent hippocampal representation of the context. In addition, all active direct and indirect path synapses on the active DG and CA3 cells become potentiated, as do all the presynaptically and postsynaptically coactive CA3 recurrent network synapses. In the future, when placed in the encoded context, with BACON working in retrieval mode, CA3 cells combine input from the direct and indirect paths (excitation reaching CA3 via each path is proportional to the amount of input from cortex that arrives via potentiated synapses), and the $\mathrm{K}_{\mathrm{CA} 3}$ most excited CA3 cells fire. If the system has stored multiple somewhat similar contexts, the CA3 cells firing will be a mix of representation cells of the current and other similar contexts (Leutgeb et al., 2007; consistent with data of Deng et al., 2013), although those representing the current context will be the most numerous. The recurrent collateral system then operates on this input and completes whichever representation had the most cells active before the recurrent input, suppressing all others.

The EC-hippocampal circuit is an approximately one-one hundredth abstraction of rat cortex-hippocampus circuitry as depicted by Treves and Rolls (1994) and O'Reilly and McClelland (1994). There were 10,000 DG cells; 3000 CA3 cells; $\mathrm{K}_{\mathrm{DG}}$ and $\mathrm{K}_{\mathrm{CA} 3}=60$; and $1000 \mathrm{EC}$ cells providing input to hippocampus and a corresponding 1000 receiving output from it. Each DG and CA3 cell was innervated by a random $60 \mathrm{EC}$ cells. The model was configured so that fear was learned entirely by potentiating synapses between a hippocampal representation of the context and amygdala fear-causing cells; direct cortical input to the amygdala was not involved in context fear for reasons given in the study by Krasne et al. (2011). During recall, the direct path input from EC to CA3 was onethird the strength of the indirect path input via DG; this value was chosen because it gave maximal ability to distinguish similar contexts correctly (Krasne et al., 2015).

In our simulations, contexts were composed of 100 EC-coded attributes from a set of 1000 possible attributes. All contexts had 50 general attributes in common (thought of as characteristics of the general laboratory environment) and 50 attributes specific to a particular context. To emulate the fact that animals in an experiment would already be familiar with various laboratory contexts (e.g., due to handling, exposure to the laboratory), all experiments were preceded by pre-exposure to several contexts composed of all 50 of the general laboratory attributes plus 50 attributes drawn at random from the 950 possible context-specific attributes. These pre-exposures were long enough for sampling of 90 of 100 attributes in a context. Pre-exposure is represented as context B exposure in Figure 6.

Simulations of the behavioral experiments proper consisted of two or three 10-min-long sessions. In all simulations, conditioning occurred in an unfamiliar context, context $\mathrm{A}$, where a shock was given just before the end of the session, and this was followed by a recall session in either context A or a similar context (context C) having 95\% of its attributes in common with context $\mathrm{A}$. In most simulations context $\mathrm{C}$ was unfamiliar; however, in the final experiment of the paper, the conditioning session in context A was preceded by a 10-min-long pre-exposure session in context $\mathrm{C}$. The scoring of freezing during recall sessions was always for the first four nominal minutes of the session. The rate of (random) sampling of contextual attributes by BACON decayed as a double exponential ( sum of a fast and a slow decay) such that $95 \%$ of the attributes of the context were sampled by the end of the nominally 10 min session, and $87 \%$ during the first $4 \mathrm{~min}$.

The computational cycle of the program repeated every one-fifth nominal seconds. For the purposes of the simulations it was assumed that in our experiments optogenetic suppression of DG silenced $50 \%$ of BACON's 10,000 DG cells and that the number of cells firing in DG during encoding, when a KWTA rule controlled firing, was reduced from 60 to 23 (i.e., $\sim 40 \%$ of normal).

The use of the direct and indirect paths together for recall provides more information about the environment than would either pathway alone and therefore minimizes retrieval errors; moreover, optimal performance is achieved when the indirect pathway is approximately three times more effective than the direct one. However, either pathway alone works well so long as very similar contexts do not have to be discriminated. The use of the DG, with its especially high number of cells and KWTA behavior, to determine which cells will become part of a representation during encoding minimizes the overlap between one representation and another and thereby prevents confusions between representations during recall. However, in the absence of input from DG during encoding, KWTA 

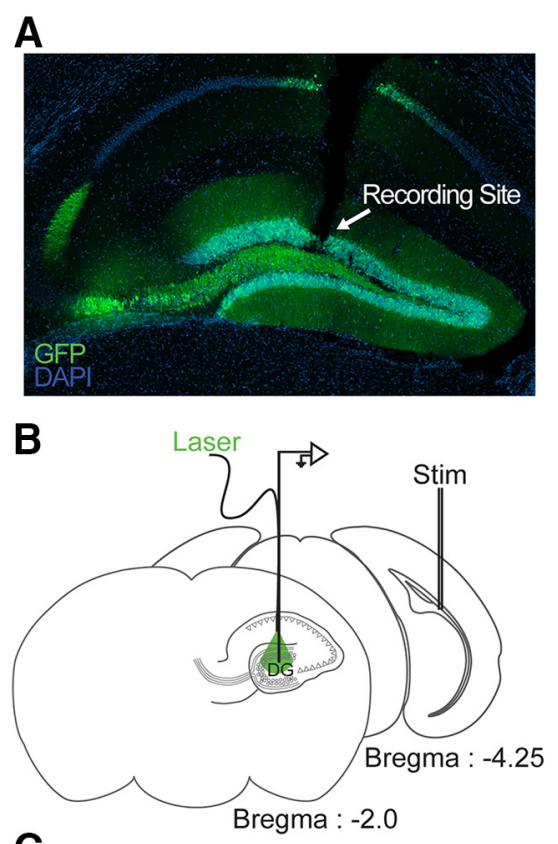

C

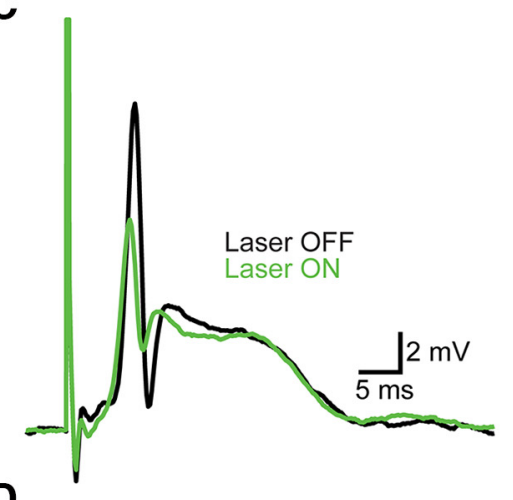

D

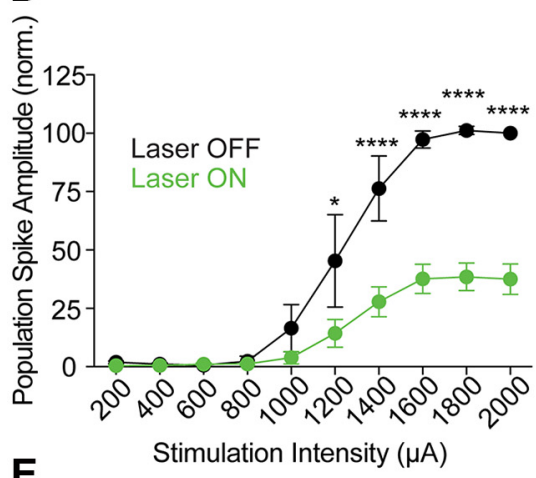

E

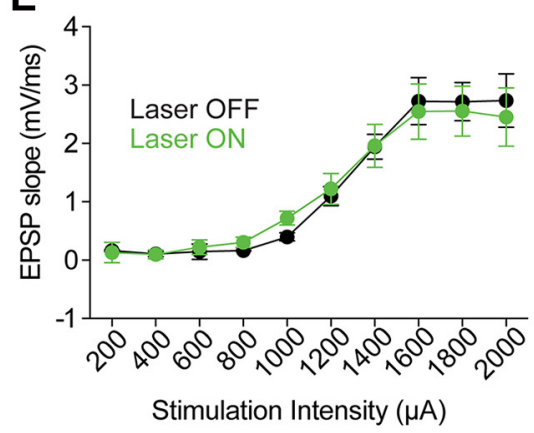

Figure 1. In vivo optogenetic inhibition of perforant path-evoked population responses in DG. A, AAV microinjection produced robust eNpHR3.0-sfGFP expression in the dorsal DG. An electrolytic lesion was made to mark recording location. The electrode and optic fiber track can properties of $\mathrm{CA} 3$, working on excitation produced by the direct pathway, cause satisfactory encoding, although very similar contexts encoded in this way are more subject to confusion than if DG had operated normally.

Data analysis. Data were analyzed using ANOVA and repeatedmeasures (RM) ANOVA where appropriate. Significant interaction effects were probed using Holm-Sidak or Bonferroni pairwise comparisons. Analyses were performed in JMP (SAS Institute; RRID:SCR_014242) or Prism (GraphPad Software; RRID:SCR_002798). The $\alpha$ value was set at 0.05 for all analyses.

\section{Results}

Optogenetic inhibition of DG neural activity

DG neural activity was inhibited in vivo using the light-activated chloride pump halorhodopsin (eNpHR3.0-sfGFP; Royer et al., 2012), which was expressed from a human synapsin promoter (Schoch et al., 1996) using a recombinant adeno-associated virus (AAV). There was robust expression of eNpHR3.0-sfGFP in DG, as judged by fluorophore abundance, 2-3 weeks after the viral injection. Expression was confined to the dorsal DG, including the hilus, with minimal expression in CA3 and other hippocampal subregions (Fig. 1A). Suppression of DG neural activity was confirmed using electrophysiological recordings of perforant pathevoked population responses from the DG of anesthetized mice (Fig. $1 B$ ). Input-output relationships, EPSP slope, and population spike amplitude were measured with and without light-mediated inhibition (532 nm, 7-9 mW). Although eNpHR activation had no effect on EPSP slope, it significantly reduced the amplitude of population spikes (Fig. 1C-E). Two-way RM-ANOVA on the population spike amplitude yielded a significant main effect of laser illumination $\left(F_{(1,4)}=20.94, p=0.0102\right)$ and stimulation intensity $\left(F_{(9,36)}=\right.$ $64.84, p<0.0001)$, as well as a significant interaction $\left(F_{(9,36)}=13.14\right.$, $p<0.0001)$. Post hoc pairwise comparisons (Holm-Sidak) confirmed significant differences between laser on and off conditions at stimulation intensities of $\geq 1200 \mu \mathrm{A}$. Together, these data demonstrate effective inhibition of dorsal DG activity in vivo by eNpHR.

To evaluate the spatial extent of DG inhibition, we assessed the ability of eNpHR to block novelty-induced IEG expression. Mice expressing eNpHR3.0-sfGFP in DG (DG-Halo mice) were allowed to explore a novel environment for $15 \mathrm{~min}$ while the DG was inhibited with green light (532 nm, 7-9 mW) via optical fibers implanted over DG. Control DG-Halo mice were not given laser illumination during novel environment exposure. In addition, a home-cage control group of DG-Halo mice was killed without exposure to the novel environment. Novel environmentexposed mice were killed 90 min following the exposure. Novel environment exposure caused a reliable increase in expression of the IEG Arc in the DG granule cell layer in control mice compared with home-cage controls (Fig. 2B,C). Inhibition of DG blocked the novelty-induced increase in Arc expression, leaving Arc expression at the level of home-cage control mice (Fig. $2 B-$ $F)$. One-way ANOVA on the number of $\mathrm{Arc}^{+}$cells $/ \mathrm{mm}^{2} / \mathrm{section}$ in dorsal DG (Fig. $2 F$ ) yielded a significant effect of experimental condition $\left(F_{(2,26)}=8.511, p<0.005\right)$. Post hoc pairwise comparisons (Holm-Sidak) confirmed that novel environment exposure elevated the density of $\mathrm{Arc}^{+}$cells in the absence of DG inhibition (home-cage vs no optogenetic inhibition, $p<0.01$ ), and this

$\leftarrow$

be seen above it. $\boldsymbol{B}$, In vivo electrophysiological recording configuration. $\boldsymbol{C}$, Sample traces of population response with and without laser inhibition. $\boldsymbol{D}$, Input- output curve for population spike amplitude showing significant inhibition during laser illumination. $\boldsymbol{E}$, Input- output curve for EPSP slope showing no effect of laser illumination $(n=3) .{ }^{*} p<0.05 ;{ }^{* * * *} p<0.001$. Data in $\boldsymbol{D}$ and $\boldsymbol{E}$ are represented as the mean \pm SEM. 

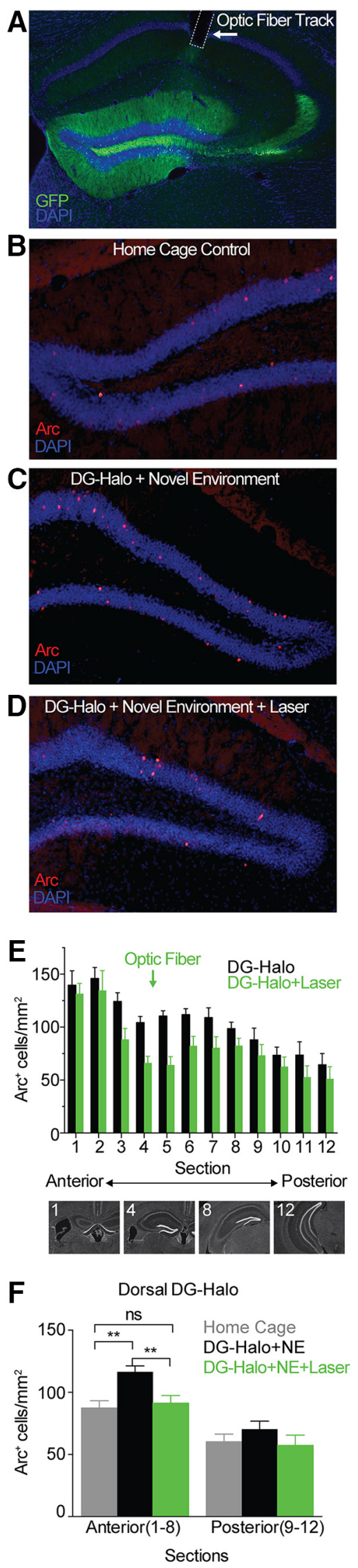

Figure 2. Optogenetic inhibition of dorsal DG activity in vivo. $\boldsymbol{A}$, Representative example of eNpHR3.0 -sfGFP expression in the dorsal DG. The optic fiber implant track is marked with dashed lines and arrow. $\boldsymbol{B}$, Arc expression in home-cage control. $\boldsymbol{C}, \boldsymbol{D}$, Laser illumination blocks
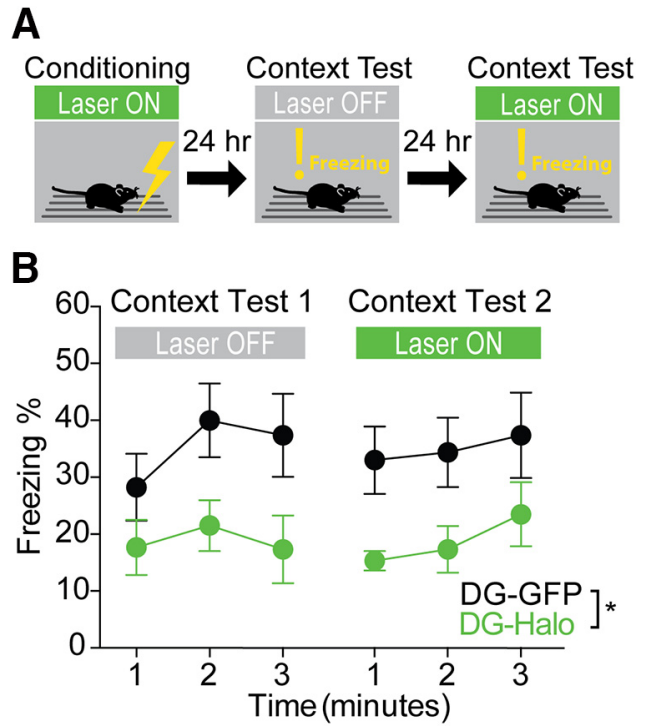

Figure 3. Optogenetic inhibition of the dorsal DG impairs acquisition of CFC. $A$, Experimental design. $\boldsymbol{B}$, Time course of freezing during successive context tests with and without laser illumination of the DG. DG inhibition during conditioning led to reduced freezing regardless of the status of DG during context test. DG-GFP mice, $n=8$; DG-Halo mice, $n=7$. Data are represented as the mean \pm SEM.

effect was blocked by optogenetic inhibition (inhibition vs no inhibition, $p<0.01)$. As expected, Arc expression in the posterior/ventral DG (outside the area of viral infection) was not affected by laser illumination (Fig. 2E,F). One-way ANOVA of $\mathrm{Arc}^{+}$cell density in posterior DG confirmed a lack of effect by novel environment exposure and optogenetic inhibition (Fig. 2E; $\left.F_{(2,26)}=0.9616, p=0.3955\right)$. The data confirm that optogenetic inhibition blocked novelty-induced DG activation throughout the dorsal DG.

\section{DG neural activity is required for acquisition of CFC but not retrieval}

Based on previous reports (Lee and Kesner, 2004; Drew et al., 2010; Kheirbek et al., 2013), we expected that inhibiting DG during CFC training would impair fear memory acquisition. DGHalo mice or control mice expressing eGFP (DG-GFP) were administered CFC with laser illumination of the DG during the conditioning session (Fig. 3A). Mice were returned to the conditioning chamber the following day with opaque dummy ferrules placed between the laser patch cable and the fiber implant. This configuration completely blocked light entry into the brain, while maintaining any ambient green light escaping from the patch cable that could serve as a contextual cue. DG-Halo mice displayed reduced freezing behavior during the context test compared with controls (Fig. 3B). The effect of suppressing DG during CFC training may mean that DG neural activity is required for CFC acquisition. Alternatively, it could reflect statedependent learning in which the experimental manipulation (DG suppression) itself becomes part of the fear context. To rule out state-dependent effects, we conducted a second context test

$\leftarrow$

induction of Arc by novel environment exposure in DG-Halo mice. $\boldsymbol{E}$, Frc $^{+}$cell density by section in DG-Halo mice with and without laser illumination. Representative sections are shown below the graph. $F$, Laser illumination prevented the novelty-evoked Arc induction in dorsal DG. DGHalo mice with laser illumination, $n=10$; DG-Halo mice without laser illumination, $n=11$; home-cage controls, $n=8 .{ }^{* *} p<0.01$. Data in $\boldsymbol{E}$ and $\boldsymbol{F}$ are represented as the mean $\pm \mathrm{SEM}$. 
with continuous laser illumination of the DG, thus recreating the conditions prevailing during acquisition (Fig. 3A). DG-Halo mice again displayed reduced freezing compared with controls (Fig. 3B). RM-ANOVA on the freezing data from the two context tests confirmed a significant main effect of virus (DG-Halo vs DG-GFP; $\left.F_{(1,13)}=7.55, p=0.0378\right)$. There was no effect of context test (with laser illumination vs without; $F_{(1,13)}<1$ ) nor did the context test interact with virus $\left(F_{(1,13)}<1\right)$. The data indicate that suppressing DG during CFC training impairs the acquisition of context fear memory.

Next, we assessed the role of DG in fear memory retrieval. A new cohort of DG-Halo and DG-GFP mice was conditioned with no laser illumination. On the following day, mice received a $5 \mathrm{~min}$ exposure to the training context without shock during which the DG was continuously illuminated. There was no difference in freezing between groups (Fig. $4 B ; t_{(25)}=0.1875, p=0.8528$ ), which is consistent with a previous report suggesting that DG may not be required for the retrieval of context fear memories or expression of freezing behavior (Kheirbek et al., 2013).

\section{Inhibition of dorsal DG impairs acquisition but not retrieval of context fear extinction learning}

The fear retrieval test is also an extinction training session. Extinction is thought to entail learning not to respond, rather than erasure of the original learning (Pavlov, 1927; Bouton, 2002; Myers and Davis, 2002). Extinction of context fear requires that the fear itself be evoked and thus depends on hippocampal recall processes. Although the extinction of fear is often thought to depend on changes within the amygdala and prefrontal cortex (Milad and Quirk, 2012; Trouche et al., 2016), there is evidence that it may also involve learning within the hippocampus itself (Corcoran et al., 2005; Tronson et al., 2012). Insofar as hippocampal learning and recall depend upon DG, it is possible that DG suppression would affect context fear extinction learning and its retrieval. We therefore investigated the role of DG in extinction.

The mice used in the retrieval experiment were administered an additional four daily 5 min shock-free context exposures with continuous DG illumination. In these context exposures (exposures 2-5), freezing of DG-Halo mice exceeded that of control mice, suggesting that inhibiting DG attenuated extinction of context fear (Fig. 4B). RM-ANOVA on sessions 2-5 confirmed a significant effect of virus $\left(F_{(1,25)}=8.20, p=0.0084\right)$. Extinction ratios (freezing in sessions 4 and 5 divided by freezing in session 1 ; Fig. 4C) were significantly lower in DG-GFP mice than in DGHalo mice $\left(t_{(21)}=2.2, p=0.038\right)$. To confirm that freezing behavior during the repeated context exposures reflected fear and not simply immobility, we included groups of DG-Halo and DGGFP mice that received five daily context exposures but were not shocked. Both groups of unshocked mice displayed low levels of freezing throughout the exposures (Fig. 4B). RM-ANOVA on days $2-5$ yielded a significant shock $X$ virus interaction $\left(F_{(1,37)}=\right.$ $4.22, p=0.0470$ ). Follow-up pairwise tests confirmed that there was a significant effect of DG suppression in shocked mice (as reported above) but not in mice that had not been shocked $\left(F_{(1,12)}<1\right.$; Fig. $\left.4 B\right)$.

To confirm that DG-Halo mice were capable of extinction learning after five sessions of illumination, all shocked mice were given an additional two sessions of extinction training without DG illumination (Fig. $4 A, B$; context tests 6-7). RM-ANOVA on sessions $6-7$ yielded a significant effect of virus $\left(F_{(1,25)}=6.6, p=\right.$ $0.0165)$. Although the virus $\times$ session interaction was not significant $(p=0.330)$, we tested the a priori prediction that the DG-
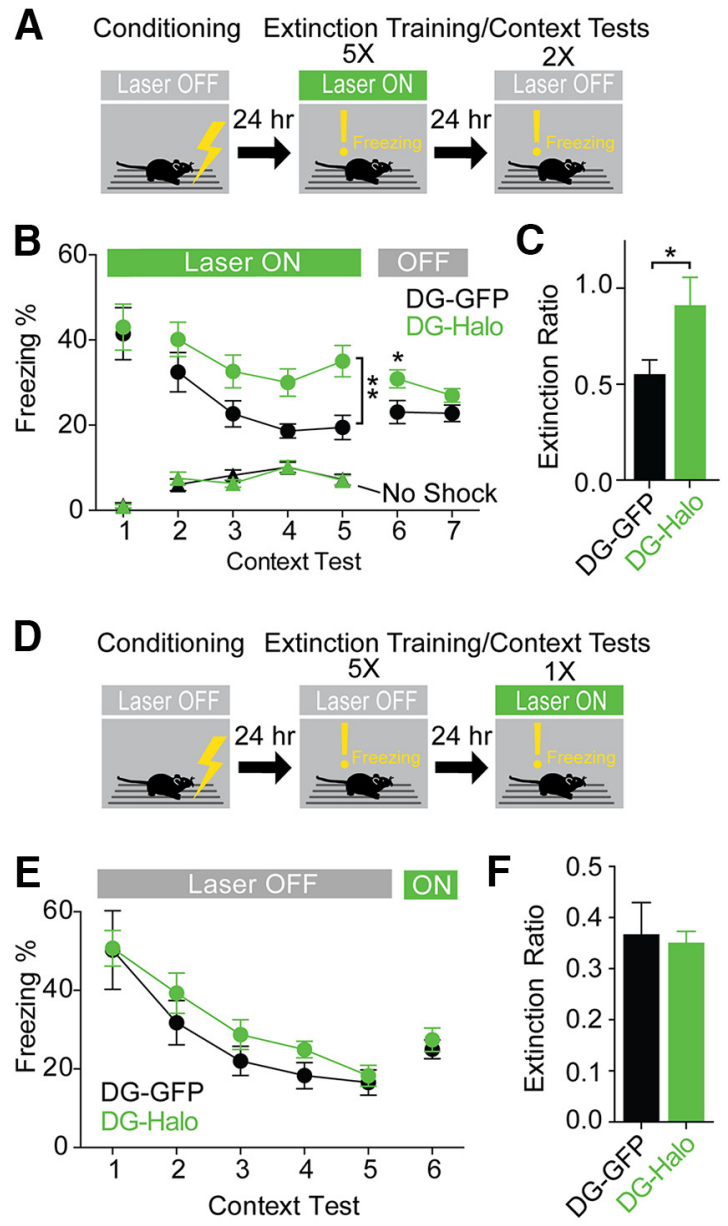

Figure 4. Optogenetic inhibition of the dorsal DG impairs context fear extinction but does not impair the expression of fear or extinction. $\boldsymbol{A}$, Experimental design. $\boldsymbol{B}$, Freezing during the seven context exposures in the absence of shock. In unshocked mice, freezing remained low across all sessions and there was no effect of optogenetic inhibition (No shock DG-Halo mice, $n=7$; No shock DG-GFP mice, $n=7$ ). In shocked mice, freezing did not differ between DG-Halo mice $(n=15)$ and DG-GFP control mice $(n=12)$ in session 1 , indicating that DG neural activity was not required for context fear expression. However, during sessions 2-5, freezing of DG-Halo mice exceeded that of DG-GFP controls, suggesting that DG suppression impaired extinction. C, Extinction ratio comparing freezing in session 1 to sessions 4 and 5 (shocked mice only). DG-GFP mice exhibited a significantly greater reduction in freezing over the course of extinction. $\boldsymbol{D}$, Design of the extinction recall experiment. $\boldsymbol{E}$, Time course of extinction showing total freezing per context test/extinction session. DG inhibition during session 6 did not affect recall of extinction learning. DG-GFP mice, $n=7$; DG-Halo mice, $n=11$. $\boldsymbol{F}$, Extinction ratio comparing freezing in session 1 to session 6 . Both groups of mice show equivalent levels of extinction. ${ }^{*} p<$ $0.05 ;{ }^{* *} p<0.01$. Data in $\boldsymbol{B}$ and $\boldsymbol{C}$ and $\boldsymbol{E}$ and $\boldsymbol{F}$ are represented as the mean \pm SEM.

GFP and DG-Halo groups would differ in session 6 but not in session 7. During session 6, the freezing of DG-Halo mice continued to exceed that of DG-GFP controls $\left(t_{(50)}=2.63, p=\right.$ $0.0112)$, but during session 7 the two groups did not differ $\left(t_{(50)}=\right.$ $1.41, p=0.1655)$. Thus, mice that received extinction training with DG silenced were able to extinguish after DG suppression was terminated. This result indicates that DG suppression did not cause permanent dysfunction.

Fear extinction involves anatomically and behaviorally dissociable acquisition and expression processes (Drew et al., 2004; Quirk and Mueller, 2008; Plendl and Wotjak, 2010). The attenuation of extinction caused by DG suppression could reflect impaired extinction learning (acquisition of extinction) or an inability to suppress fear after extinction is learned (expression of extinction). To differentiate between these accounts, new groups 
of DG-Halo and DG-GFP mice were conditioned and then given $5 \mathrm{~d}$ of extinction training without DG illumination (Fig. 4D). With DG function intact, context fear declined over the $5 \mathrm{~d}$ of extinction training (Fig. 4E), and freezing did not differ between the DG-Halo and DG-GFP groups. The data were analyzed as in the previous experiment. There was no effect of virus on freezing during the retrieval test, session $1\left(t_{(16)}=0.05, p=0.9638\right)$. During sessions $2-5$, there was a significant effect of session $\left(F_{(3,48)}=15.26, p<0.0001\right)$ but no effect of virus $\left(F_{(1,16)}=1.64\right.$, $p=0.2189)$ or the interaction $(F<1)$. After context fear reached an asymptotically low level, both groups of mice were given a final context test under continuous laser illumination of DG. Both groups exhibited a small increase in freezing between session 5 and session 6, perhaps because the introduction of light as a cue caused the renewal of fear. However, the increase in freezing was no larger in DG-Halo mice than in DG-GFP controls. In both groups, freezing in session 6 was significantly lower than the session 1 (pre-extinction) level. The data from sessions 5 and 6 were subjected to RM-ANOVA, which confirmed a significant effect of session $\left(F_{(1,16)}=9.58, p=0.0070\right)$ but no effect of virus $(F<1)$ or the interaction $(F<1)$. We also computed an extinction ratio comparing freezing in session 6 to that in session $1[6 /(6+1)$; Fig. $4 F]$. The extinction ratio did not differ between DG-Halo mice and DG-GFP controls $\left(t_{(16)}=0.29, p=0.7791\right)$, indicating that extinction produced a comparable suppression of freezing in the two groups.

\section{Simulations support a role of DG in retrieval}

The apparent lack of an effect of DG suppression on CFC expression is puzzling because it conflicts with recent reports supporting a role for DG in CFC retrieval. In particular, Denny et al. (2014) expressed the optogenetic inhibitor archaerhodopsin (Arch) in the subset of mouse DG cells active during CFC acquisition ("engram cells"). Suppressing this cell population during subsequent recall tests attenuated fear expression. Why would suppressing a small population of engram cells impair CFC retrieval, whereas suppressing a larger population of granule cells nonspecifically fails to impair CFC retrieval? To generate hypotheses as to how hippocampal circuit mechanisms might give rise to these seemingly incompatible results, we performed simulations using BACON (Krasne et al., 2015). BACON is a biologically plausible computational model of hippocampal processing in CFC that can reproduce a number of CFC phenomena, including the immediate-shock deficit, pre-exposure effects, and fear generalization (Krasne et al., 2015). BACON mimics current conceptions of EC, DG, and CA3 circuit operation during context fear conditioning and recall, while adding nonhippocampal (presumptively prefrontal) circuitry that configures the hippocampus specifically for encoding of a new representation or retrieval of an existing one, as appropriate. Encoding involves plasticity in both DG and CA3, and retrieval is mediated by activity at both EC-CA3 (direct path) and EC-DG-CA3 (indirect path) synapses (Fig. 5A; Materials and Methods).

As seen in rows 1 and 2 of Figure $5 B$, BACON simulates the finding that partial, nonspecific suppression of DG during CFC training causes a clear diminution of fear (Fig. $5 B$, row 2 ). In the simulations, this effect occurs because the number of DG cells that fire-and whose synapses therefore undergo potentiationduring training is substantially below normal; therefore, at testing, the CA3 cells associated with context A are in a minority before recurrent input, which often results in the recurrent collateral system completing the wrong representation. Because only context A had been paired with shock, the activation of a
non-A context representation fails to activate fear. The simulations also simulate the finding that partial, nonspecific suppression of DG during postconditioning testing has little effect (Fig. $5 B$, row 3 ). The model behaves in this way because the silenced input to CA3 from DG is not specific to any one context, and the input that remains is balanced with respect to the various contexts that have been encoded. In addition, input via the direct path remains normal.

We then simulated the manipulation of Denny et al. (2014), in which optogenetic inhibitor Arch is conditionally expressed in the subset of mouse DG cells active during CFC acquisition (engram cells). Consistent with the results of the study by Denny et al. (2014), during recall in BACON suppressing the subset of DG cells that were active during encoding caused pronounced fear attenuation (Fig. $5 B$, row 4 ). BACON generates this result because when only the DG cells corresponding to the conditioning context are silenced, the cells that fire during recall are likely to be ones that encode features of a different (nonfearful) context. Consequently, the activity of these remaining DG neurons biases CA3 toward retrieving a representation of a context other than the conditioning context, leading to a reduction in fear expression.

Finally, we simulated an experiment of Nakashiba et al. (2012), who found that complete suppression of DG output during both encoding and retrieval had virtually no effect on context fear conditioning. BACON emulates this result as well (Fig. $5 B$, row 5). It does so because the direct path (from EC to CA3) to CA3 can alone mediate satisfactory encoding and retrieval, so long as very similar contexts do not have to be distinguished. The results of this simulation and the others described above are schematized in Figure 6.

It should be emphasized that although our own behavioral experiments reported above do not provide direct evidence of the participation of DG in recall, the ability of BACON to emulate the results of all these experiments, as well as the aforementioned published experiments, is contingent on the participation of DG in recall. To make this clear, we repeated the simulations just described, with DG entirely suppressed during recall (Fig. 5B). Under this condition, BACON fails to reproduce the experimental results that it emulates so well when DG does participate in recall.

\section{DG suppression reduces memory precision during recall}

The BACON simulations suggest that DG contributes to CFC recall even though our behavioral experiments failed to detect an effect of DG suppression on the expression of CFC. We sought to identify task conditions under which the DG contribution to fear expression could be confirmed behaviorally. During recall, CA3 in BACON receives input both directly from EC (the direct path) and via DG (the indirect path). If distinctions between similar contexts do not need to be made, then the direct path alone is sufficient for BACON to produce normal recall of conditioning. However, if BACON must distinguish between similar feared and neutral (unfeared) contexts, the loss of DG input affects recall. For instance, if BACON is tested in a neutral context that is similar to a feared context, DG suppression increases fear, because shared features of the similar contexts cause BACON to sometimes activate the representation of the feared context rather than the neutral one. Conversely, if BACON is tested in a feared context that is similar to a neutral context, DG suppression reduces fear, because the similar neutral context representation is sometimes activated incorrectly. We undertook behavioral experiments to test these predictions with the goal of providing direct evidence for the role of DG in recall. 
A

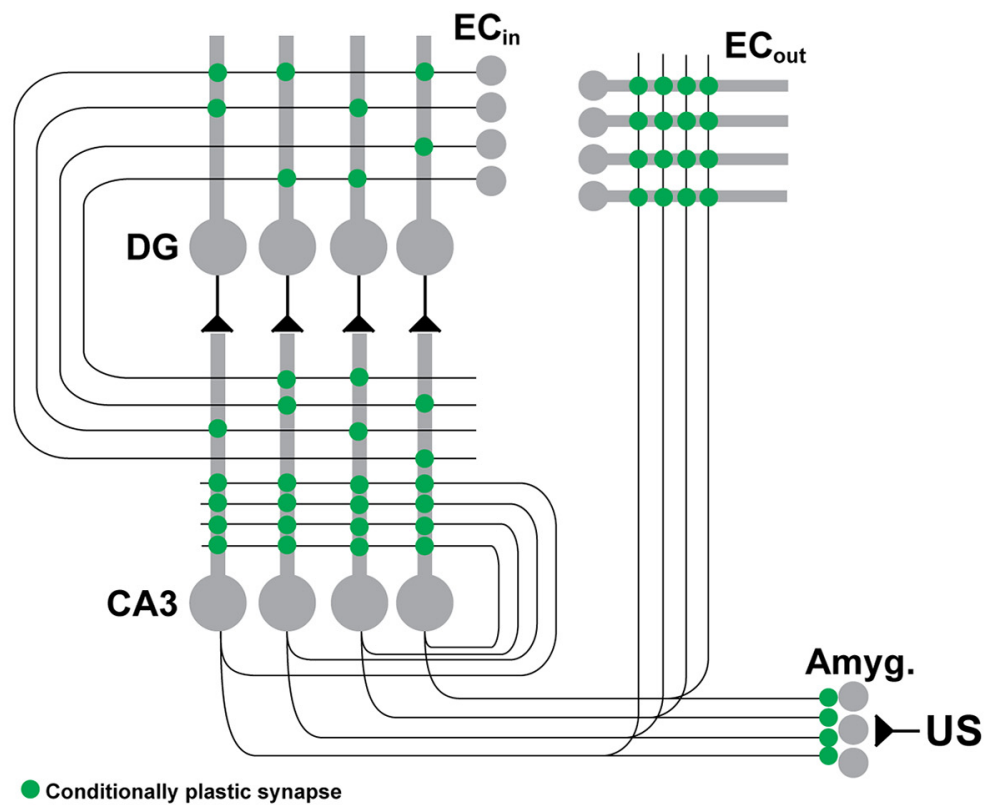

B

DG Status

\begin{tabular}{ccc} 
Conditioning & $\begin{array}{c}\text { Shock } \\
\text { Context } \\
\text { Test }\end{array}$ \\
\hline 1 & Normal & Normal \\
2 & Partial $\downarrow$ & Normal \\
3 & Normal & Partial $\downarrow$ \\
4 & Normal & $\begin{array}{c}\text { Engram Cells } \\
\text { Total } \downarrow\end{array}$ \\
5 & Total $\downarrow$ & Total $\downarrow$
\end{tabular}

Experimental Data Freezing (\% Control) $\begin{array}{llllll}0 & 20 & 40 & 60 & 80 & 100\end{array}$

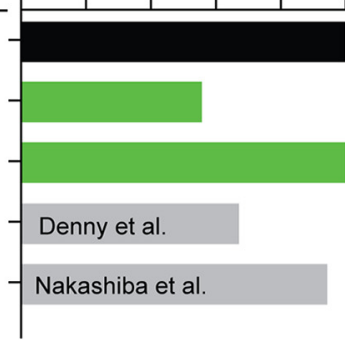

BACON Freezing ( $\%$ Control)

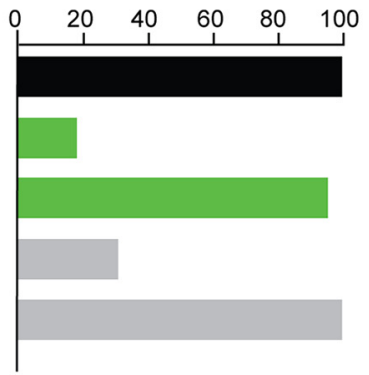

BACON No DG in Recall Freezing (\% Control)

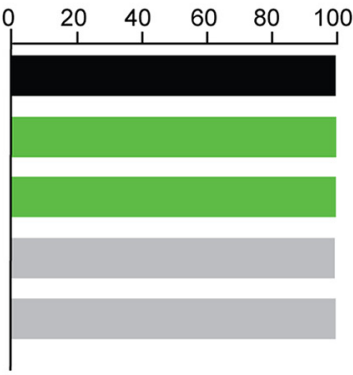

Figure 5. The BACON computational model of hippocampal function reproduces the behavioral effects of a variety of DG manipulations. $A$, The BACON cortex-hippocampus-amygdala circuit includes 1000 entorhinal cortex neurons ( $\mathrm{EC}_{\mathrm{in}}$ ) projecting to $10,000 \mathrm{DG}$ granule cells. The $3000 \mathrm{CA} 3$ neurons are innervated by $\mathrm{EC}_{\mathrm{in}{ }^{\prime}} \mathrm{DG}$, and recurrent collaterals from other CA3 pyramidal cells. CA1 is omitted from the model. $\mathrm{EC}_{\text {out }}$ and amygdala are innervated directly by $\mathrm{CA3}$ pyramidal neurons. The CA3-amygdala projection allows fear to become conditioned directly to hippocampal context representations. Context fear memory acquisition depends on plasticity at $\mathrm{EC}_{\mathrm{in}}-\mathrm{DG}, \mathrm{EC} \mathrm{C}_{\mathrm{in}}-\mathrm{CA3}, \mathrm{CA3}-\mathrm{CA} 3$, and $\mathrm{CA3}$-amygdala synapses, which are highlighted in green. The $\mathrm{DG}-\mathrm{CA3}$ projection operates during both memory acquisition and retrieval. A complete description is available in Krasne et al. (2015). B, Experimental data (left) from the current study (rows 1-3) and two previously published studies (Nakashiba et al., 2012; Denny et al., 2014; rows 4-5) compared with predictions from BACON simulations. The middle column shows the results of simulations in which BACON used DG during recall. The right column represents simulations in which BACON was prevented from using DG during recall. The labels at left denote the degree of DG suppression during conditioning and test sessions. Bars represent freezing during the test session as a percentage of freezing in control conditions. BACON recapitulates the seemingly contradictory behavioral results only when it is allowed to use DG during recall.

In the first experiment, cohorts of DG-Halo mice or DG-GFP mice were conditioned in the absence of DG illumination and then received two context tests with continuous DG illumination. The first test occurred in a neutral context (context $\mathrm{C}$ ) that shared multiple features with the shocked one, and the second occurred in the shock context itself (Fig. 7A). As expected, DG-GFP mice discriminated between the two contexts, as evidenced by higher freezing in the shock context than in the neutral one (Fig. $7 B$ ). As predicted, the DG-Halo mice did not distinguish well between the two contexts, freezing at similar levels in both context tests (Fig. $7 B$ ). RM-ANOVA of the freezing data from the two context tests yielded a significant virus $\times$ context interaction $\left(F_{(1,18)}=\right.$ 7.97, $p=0.0113$ ). Follow-up pairwise comparisons confirmed that freezing in the shocked context exceeded that in the neutral context in DG-GFP control mice (Holm-Sidak test: $t_{(9)}=3.99$, $p=0.0063)$ but not in DG-Halo mice $\left(t_{(9)}=0.28, p=0.9547\right)$. Furthermore, as predicted, in the neutral context freezing of DG-
Halo mice exceeded that of DG-GFP mice $\left(F_{(1,9)}=14.20, p=\right.$ $0.0044)$, but this was not the case in the shocked context $(F<1)$. The discrimination index ([Shock - Neutral]/[Shock + Neutral]) also differed significantly between groups $\left(t_{(9)}=2.87\right.$, $p=0.0184$; Fig. $5 C$ ).

In the experiment just reported, the generalization test occurred in a novel context. As a result, at least in the simulations, the expression of fear in the generalization context was influenced by recall as well as by encoding of the context. As elaborated in the Discussion, the increased fear observed with DG suppressed may thus reflect a role of DG in encoding rather than in recall. The second experiment was designed to more definitively demonstrate a role for DG in recall. Mice were pre-exposed to the neutral context and conditioned in the similar shock context without DG manipulation. Then they were tested in the shocked context with or without DG suppression. Because representations of both contexts were created before the test, any 


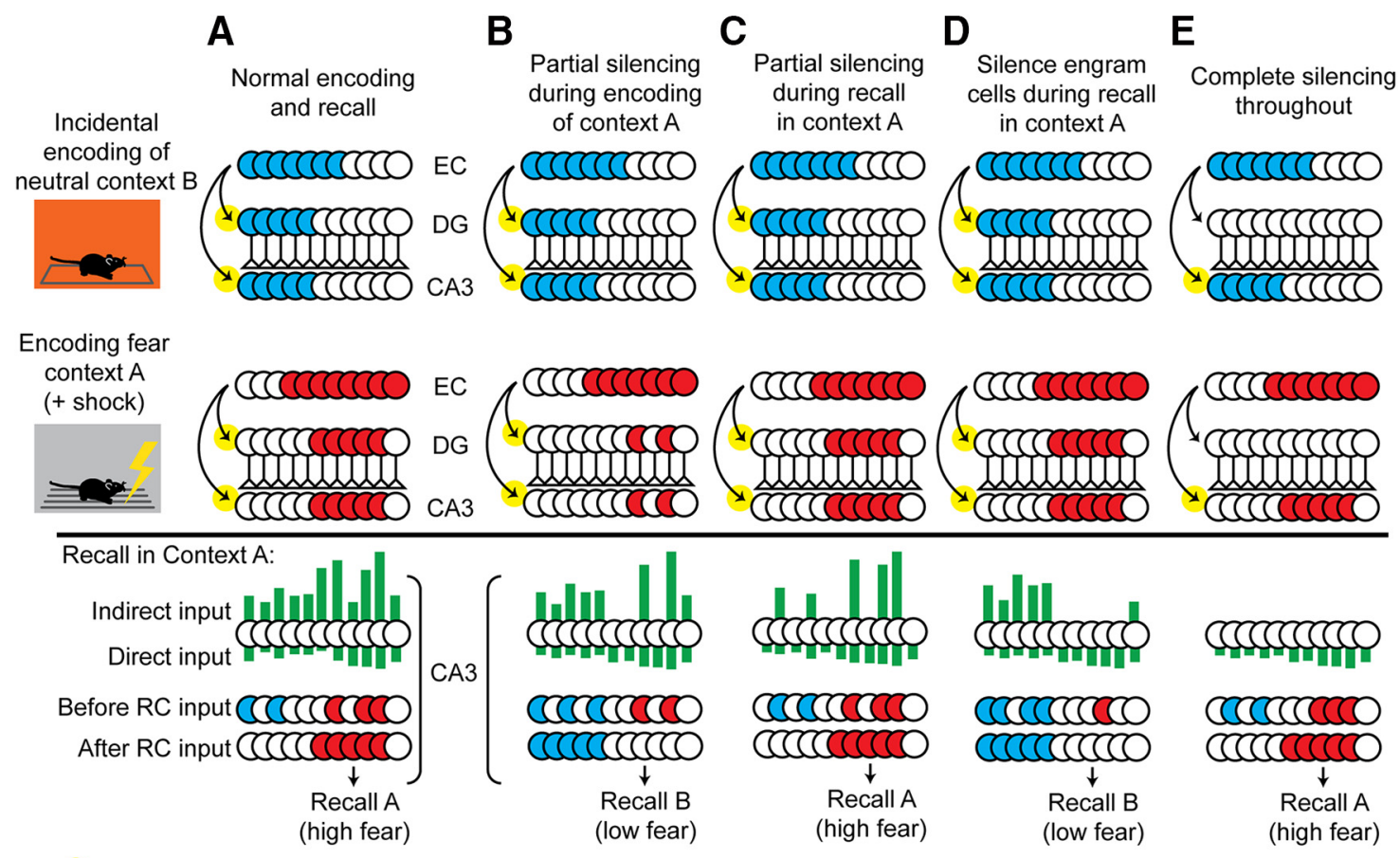

Potentiation of co-active synapses

Figure 6. The effects of $D G$ silencing on acquisition and recall of context fear: proposed mechanisms. $A$, To simulate incidental encoding of places other than the conditioning context, the subject is exposed to (and encodes) a neutral context (context B) before being fear conditioned in a different context (context A). Then the subject is tested for fear recall in context A. EC, DG, and CA3 are portrayed as linear arrays of cells, with cells involved in the processing of each context grouped. Active cells are filled in red or blue. The EC cells activated by contexts A and B overlap. During encoding, $D G$ recodes the $E C$ representations to form relatively sparse, nonoverlapping codes for each context, and each DG cell drives a corresponding CA3 neuron. Each DG and CA3 cell is innervated via Hebbian synapses by a random subset of $\mathrm{EC}$ neurons. EC-DG, EC-CA3, and CA3-CA3 [recurrent collateral (RC)] synapses of coactive cells become potentiated, providing a basis for later recognition of the encoded contexts. During tests in which only some fraction of the attributes of a context may have been sampled, CA3 cells are excited via the potentiated synapses of the indirect (EC-DG-CA3) and direct $(E C-C A 3)$ paths, but the indirect path is dominant. The $k$ most excited $\mathrm{CA} 3$ cells fire, and the recurrent collateral system then completes the representation, which determines input to the amygdala and hence fear responses. $B$, When a random subset of $D G$ neurons is suppressed during encoding of context $A$, a subnormal number of $D G$ cells is incorporated into the context $A$ representation. As a result, the context $B$ representation dominates during recall. $C$, When a random subset of $D G$ neurons is suppressed during recall, representation cells of both context $A$ and $B$ receive less indirect path input, but the remaining direct and indirect inputs are sufficient to cause the representation of context $A$ to be completed. $D$, When all DG cells that were active during the encoding of context A (engram cells) are suppressed during recall, the active cells are necessarily those representing context $B$. The context $B$ representation is completed, and fear is low. $E$, When $D G$ activity is totally suppressed during both encoding and recall, direct input to $C A 3$ is adequate to cause representation of context $A$ to emerge and evoke fear.

effects of DG suppression during the test should reflect the contribution of DG to recall rather than to encoding.

New cohorts of DG-Halo and DG-GFP mice were pre-exposed to the similar context, context $\mathrm{C}$, before fear conditioning in context A. Then, DG was illuminated during the subsequent test session in context A (Fig. 7D). During the test session, DG-Halo mice displayed a significant reduction in freezing compared with DG-GFP controls (Fig. 7E). RM-ANOVA on the freezing data from the test session confirmed a significant effect of virus $\left(F_{(1,28)}=7.579, p=\right.$ 0.0102). Simulations and behavioral data for the experiment are compared in Figure 7F. As in the previous simulations, BACON could reproduce the empirical results only when DG was allowed to participate in recall. This experiment strongly supports the involvement of DG in recall.

\section{Discussion}

We have confirmed that the DG has a robust role in context fear memory acquisition and demonstrated its participation in retrieval and extinction learning. Optogenetic suppression of dorsal DG activity during context fear training impaired acquisition of CFC. In our initial experiments, suppressing DG during reexposure to the training context did not impair the expression of fear memory but attenuated fear extinction. Although DG neural activity was not required for the expression of fear in the trained context, the contribution of DG to recall was re- vealed in two procedures that challenged mice to distinguish between similar contexts. When a neutral context was similar to the shocked context, suppression of DG impaired the ability of mice to correctly express fear in the conditioned context and not in the neutral one.

Simulations using a biologically plausible model that incorporates conventional views of hippocampal contextual processing (BACON) indicated that most of our observations, as well as several important findings in the literature that may seem contradictory, are in fact all consistent with the hypothesis that DG is normally used during both acquisition and retrieval. The simulations closely paralleled the behavioral data when the model used DG during both acquisition and recall but not when DG was prevented from contributing to recall. It should be emphasized that the point of our simulation studies was not to test the validity of the BACON model, but rather was to determine whether (and how) the conventional views of hippocampal function that are built into the model could emulate both our own findings and seemingly discrepant ones.

\section{The DG and retrieval}

The relevance of DG to recall of hippocampal representations has been questioned both on theoretical grounds and based on evidence that DG suppression during recall has no apparent behavioral effect. In particular, our initial experiments and earlier 
A

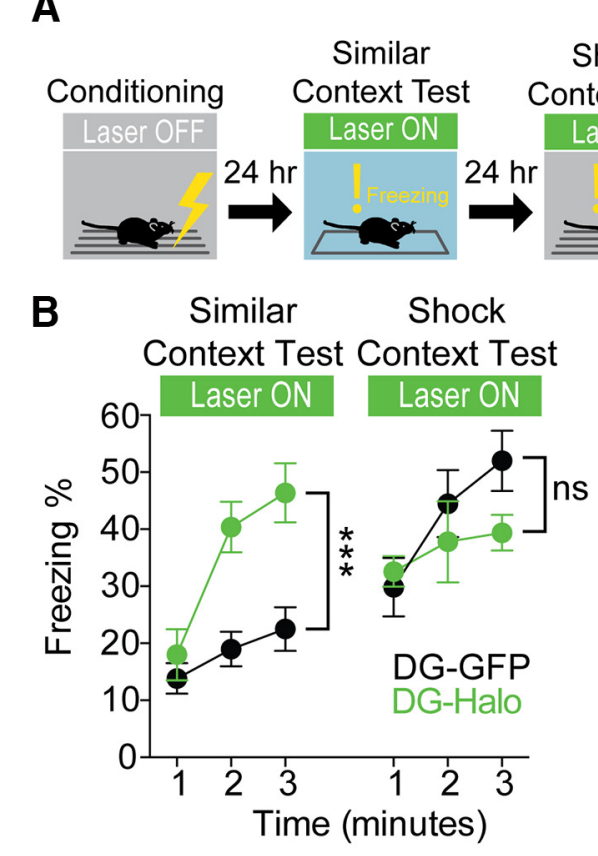

D

F DG Status

Experimental Data

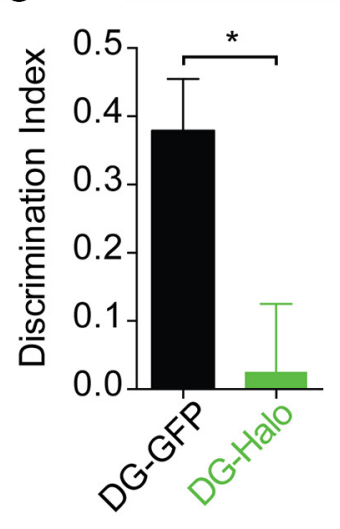

Similar Context Pre-exposure

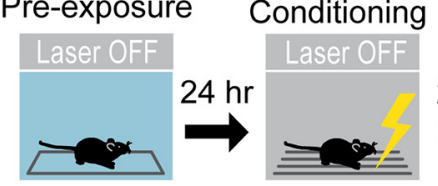

E

E Shock
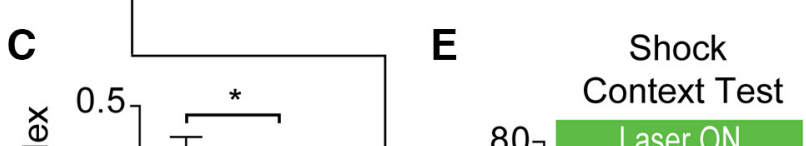

DG Status

Similar

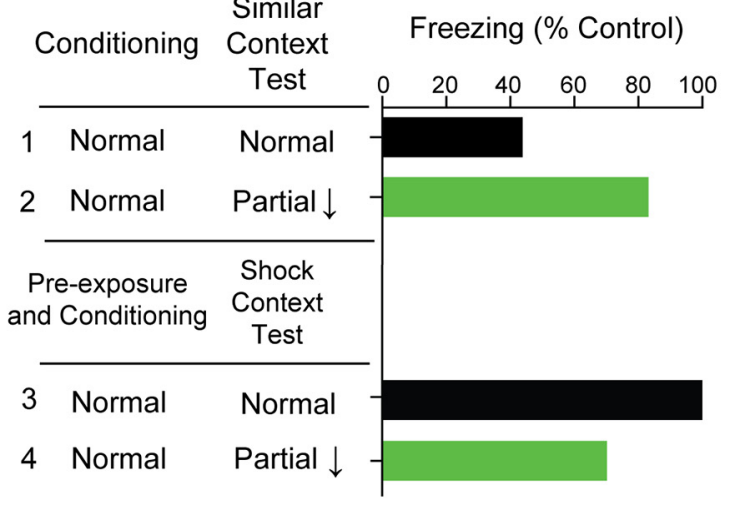

Freezing (\% Control)

Freezing (\% Control)
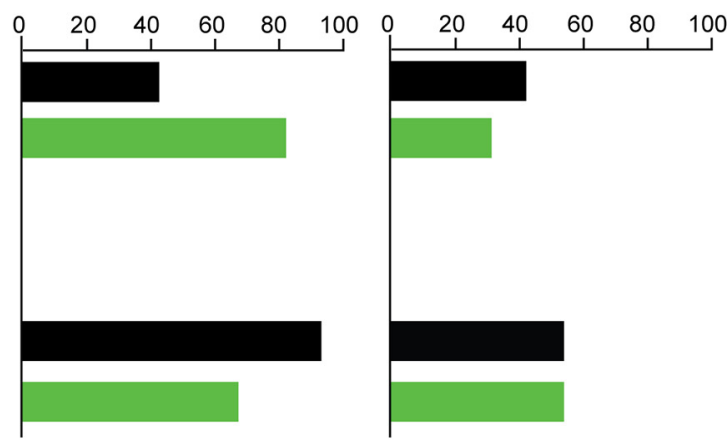

Figure 7. Optogenetic inhibition of the dorsal DG affects fear expression when similar contexts must be distinguished. $A$, Design of an experiment testing fear generalization in a context similar to the conditioning context. $\boldsymbol{B}$, Time course of freezing during the generalization test and shock context test with laser inhibition of the DG. DG inhibition during fear expression caused elevated freezing in the neutral generalization context relative to controls but did not affect freezing in the shock context. C, Discrimination index ([Shock-Neutral]/ [Neutral + Shock]) demonstrating that DG-GFP mice discriminated between contexts but DG-Halo mice did not. DG-GFP mice, $n=6$; DG-Halo mice, $n=5$. $D$, Design of an experiment in which mice were pre-exposed to a neutral context before conditioning in a similar context. $E$, Time course of freezing during shock context test with DG inhibition. DG inhibition reduced fear expression. DG-GFP mice, $n=16 ; D G-H a l o$ mice, $n=16$. ${ }^{*} p<0.05 ;{ }^{* * *} p<0.005$. Data are represented as the mean \pm SEM. $F$, Comparison of behavioral results and the corresponding BACON simulations. Behavioral results are shown in the left column. BACON simulations are shown in the middle and left columns. The simulations were performed with BACON using DG during recall (middle) or with BACON prevented from using DG during recall (right). The generalization experiment depicted in $\boldsymbol{A}$ is shown in rows $1-2$. The pre-exposure experiment depicted in $\boldsymbol{D}$ is shown in rows $3-4$. Bars represent freezing during the test session as a percentage of freezing in control animals. The simulations recapitulate the observed effects of DG suppression only when BACON uses DG during recall.

published results (Nakashiba et al., 2012; Kheirbek et al., 2013) show that extensive DG suppression can fail to block the expression of conditioned context fear.

However, other reports suggest that DG is in fact used to access CA3 during recall. Optogenetic activation of the dentate granule cells that participated in $\mathrm{CFC}$ acquisition (i.e., engram cells) is sufficient to evoke fear in a novel context (Liu et al., 2012; Ramirez et al., 2013; Redondo et al., 2014; Ryan et al., 2015), suggesting that the activity of DG cell ensembles can initiate context memory retrieval, although this does not prove that DG is used during natural recall. More direct evidence for a role of DG in natural recall is provided by the finding that selectively suppressing the relatively small group of engram cells attenuates CFC expression during re-exposure to the trained context (Denny et al., 2014).

It may seem paradoxical that suppressing a relatively small group of cells during retrieval has a substantial effect in the Denny et al. (2014) experiments, whereas suppressing a much larger group of cells in our own study and the study by Kheirbek et al. (2013) has no effect. However, the simulations performed using BACON suggest that these apparently discrepant observations are not in fact inconsistent. As explained in Results and conceptualized in Figure 6, the suppression of a large random set of cells during recall does not prevent accurate recall because the indirect path input to CA3 that remains, together with direct path input, are sufficient for correct recall, so long as very similar contexts do 
not have to be discriminated. However, when only DG cells that were active during encoding are selectively suppressed, the DG cells that remain active are those of normally encoded, nonfeared contexts. As a result, the nonfeared contexts are recalled, and little fear is expressed. The idea that suppression of a sparse neuronal ensemble in hippocampus can lead to artificial activation of a different ensemble and thereby influence memory performance is supported by recent IEG studies (Tanaka et al., 2014; Stefanelli et al., 2016) and electrophysiological recordings (Trouche et al., 2016).

Although context fear can be retrieved in the absence of neural activity in DG, the BACON simulations and our behavioral experiments illustrate that this comes at the cost of impaired recall accuracy. The impairments in accuracy were revealed in two experiments in which mice were challenged to distinguish between the conditioning context and a similar neutral one. When mice were conditioned in one context and then tested in a similar neutral one that was new to them, the suppression of DG increased the generalization of context fear. However, when mice were first pre-exposed to the neutral context and then fear conditioned and tested, the suppression of DG increased generalization from the neutral context to the similar conditioning context. Although both of these findings appear to reflect the role of DG in minimizing interference among different context representations, BACON simulations suggest that two distinct mechanisms can be involved. BACON predicts that when, as in the first experiment, the neutral similar context is novel at the time of the generalization test, DG participates in the encoding of its representation during the test itself. Fear expression during the test therefore depends on competition for retrieval between representations of the newly encoded context and the conditioning context. Suppressing DG during the first exposure to the neutral context would impair its encoding, thereby putting it at a disadvantage when competing with the (normally encoded) conditioning context during the generalization test. Thus, in the first experiment the increased fear generalization during DG suppression may reflect impairments to encoding as much as to retrieval. In contrast, when, as in the second experiment, both the neutral context and the conditioning context are encoded before any manipulation of DG, the effect of DG suppression must reflect participation of DG in recall. The BACON simulations suggest that DG contributes to recall by enhancing the probability that CA3 pattern completes the correct representation from among similar context representations.

\section{The DG and extinction}

A wide range of observations suggests that extinction is an independent, highly context-specific form of learning to inhibit fear, not an erasure of the fear itself. Indeed, since the time of Pavlov extinction has been hypothesized to constitute new learning rather than unlearning because the original learned response can resurface with the passage of time after extinction (Pavlov, 1927), after a context shift (Bouton, 2004), or via other behavioral manipulations (Rescorla and Heth, 1975; Bouton, 2002). Extinction and acquisition memories appear to coexist, with different situations favoring retrieval of one memory or the other. The hippocampus has been hypothesized to control this selective retrieval. For instance, the renewal of fear of a tone conditioned stimulus (Bouton and Bolles, 1979) activates hippocampal projections to prefrontal cortex (Jin and Maren, 2015) and is impaired by hippocampal lesions, leading to the hypothesis that hippocampal mechanisms govern retrieval of fear versus fear extinction memories (Ji and Maren, 2007).
The role of hippocampus in the extinction of contextual fear is less clear. Certainly, one role is to activate the fear responses that are a precondition for extinction learning. However, because the suppression of DG did not impair fear expression during extinction sessions, we hypothesize that the DG contributes to extinction learning through a different mechanism. One possibility is that the absence of shock during extinction causes the conditioning context to be perceived as a new context. Consistent with this hypothesis, there is evidence that context fear extinction causes a new context representation to be generated in the hippocampus. Context fear extinction causes CA1 place cells to remap (i.e., adopt new place fields), similar to what is observed when an animal is moved from one context to another (Wang et al., 2015). In addition, context fear acquisition and extinction elicit IEG activity in unique ensembles of CA1 neurons, which have been hypothesized to support distinct acquisition and extinction memories (Tronson et al., 2009). Suppression of neural activity in DG might impair encoding of this new extinction context in the same way that suppression affects processing of the generalization context described above. Impaired encoding of the extinction context would increase the probability that the original (fearful) context representation is continually activated, thereby maintaining fear expression despite extinction training. Impaired context fear extinction has also been reported after the suppression of adult neurogenesis in DG (Deng et al., 2009; Pan et al., 2012).

\section{Summary}

Our data identify DG as contributing to both context fear learning and recall. Its role in learning encompasses both fear acquisition and fear extinction. Although context fear can be expressed in the absence of DG neural activity, the role of DG in fear expression is most directly revealed when very similar contexts must be distinguished. Our data, as well as other recent findings, could be reproduced using a physiologically realistic model of hippocampal function supposing that both memory acquisition and retrieval involve coordinated activity of DG and CA3. The findings encourage further study of DG circuit function and plasticity as a way to identify mechanisms through which context generalization, fear acquisition, and fear extinction can be modulated. Because fear generalization (Lissek et al., 2010; Kheirbek et al., 2012) and extinction (Bouton et al., 2001; Mineka and Zinbarg, 2006) are believed to play important roles in the etiology and treatment of anxiety disorders, a more thorough understanding of the DG contributions to these processes will likely help to identify more effective therapeutic strategies.

\section{References}

Aurnhammer C, Haase M, Muether N, Hausl M, Rauschhuber C, Huber I, Nitschko H, Busch U, Sing A, Ehrhardt A, Baiker A (2012) Universal real-time PCR for the detection and quantification of adeno-associated virus serotype 2-derived inverted terminal repeat sequences. Hum Gene Ther Methods 23:18-28. CrossRef Medline

Bernier BE, Lacagnina AF, Drew MR (2014) Potent attenuation of context fear by extinction training contiguous with acquisition. Learn Mem 22: 31-38. CrossRef Medline

Bouton ME (2002) Context, ambiguity, and unlearning: sources of relapse after behavioral extinction. Biol Psychiatry 52:976-986. CrossRef Medline

Bouton ME (2004) Context and behavioral processes in extinction. Learn Mem 11:485-494. CrossRef Medline

Bouton ME, Bolles RC (1979) Role of conditioned contextual stimuli in reinstatement of extinguished fear. J Exp Psychol Anim Behav Process 5:368-378. CrossRef Medline

Bouton ME, Mineka S, Barlow DH (2001) A modern learning theory perspective on the etiology of panic disorder. Psychol Rev 108:4-32. CrossRef Medline 
Corcoran KA, Desmond TJ, Frey KA, Maren S (2005) Hippocampal inactivation disrupts the acquisition and contextual encoding of fear extinction. J Neurosci 25:8978-8987. CrossRef Medline

David DJ, Samuels BA, Rainer Q, Wang JW, Marsteller D, Mendez I, Drew M, Craig DA, Guiard BP, Guilloux JP, Artymyshyn RP, Gardier AM, Gerald C, Antonijevic IA, Leonardo ED, Hen R (2009) Neurogenesisdependent and -independent effects of fluoxetine in an animal model of anxiety/depression. Neuron 62:479-493. CrossRef Medline

Deng W, Saxe MD, Gallina IS, Gage FH (2009) Adult-born hippocampal dentate granule cells undergoing maturation modulate learning and memory in the brain. J Neurosci 29:13532-13542. CrossRef Medline

Deng W, Mayford M, Gage FH (2013) Selection of distinct populations of dentate granule cells in response to inputs as a mechanism for pattern separation in mice. Elife 2:e00312. CrossRef Medline

Denny CA, Kheirbek MA, Alba EL, Tanaka KF, Brachman RA, Laughman KB, Tomm NK, Turi GF, Losonczy A, Hen R (2014) Hippocampal memory traces are differentially modulated by experience, time, and adult neurogenesis. Neuron 83:189-201. CrossRef Medline

Drew MR, Hen R (2007) Adult hippocampal neurogenesis as target for the treatment of depression. CNS Neurol Disord Drug Targets 6:205-218. CrossRef Medline

Drew MR, Huckleberry KA (2017) Modulation of aversive memory by adult hippocampal neurogenesis. Neurotherapeutics. 435:406. CrossRef

Drew MR, Yang C, Ohyama T, Balsam PD (2004) Temporal specificity of extinction in autoshaping. J Exp Psychol Anim Behav Process 30:163176. CrossRef Medline

Drew MR, Denny CA, Hen R (2010) Arrest of adult hippocampal neurogenesis in mice impairs single-but not multiple-trial contextual fear conditioning. Behav Neurosci 124:446-454. CrossRef Medline

Fanselow MS (2010) From contextual fear to a dynamic view of memory systems. Trends Cogn Sci 14:7-15. CrossRef Medline

Grieger JC, Choi VW, Samulski RJ (2006) Production and characterization of adeno-associated viral vectors. Nat Protoc 1:1412-1428. CrossRef Medline

Ji J, Maren S (2007) Hippocampal involvement in contextual modulation of fear extinction. Hippocampus 17:749-758. CrossRef Medline

Jin J, Maren S (2015) Prefrontal-hippocampal interactions in memory and emotion. Front Syst Neurosci 9:170. CrossRef Medline

Kheirbek MA, Klemenhagen KC, Sahay A, Hen R (2012) Neurogenesis and generalization: a new approach to stratify and treat anxiety disorders. Nat Neurosci 15:1613-1620. CrossRef Medline

Kheirbek MA, Drew LJ, Burghardt NS, Costantini DO, Tannenholz L, Ahmari SE, Zeng H, Fenton AA, Hen R (2013) Differential control of learning and anxiety along the dorsoventral axis of the dentate gyrus. Neuron 77:955-968. CrossRef Medline

Krasne FB, Fanselow MS, Zelikowsky M (2011) Design of a neurally plausible model of fear learning. Front Behav Neurosci 5:41. CrossRef Medline

Krasne FB, Cushman JD, Fanselow MS (2015) A Bayesian context fear learning algorithm/automaton. Front Behav Neurosci 9:112. CrossRef Medline

Lassalle JM, Bataille T, Halley H (2000) Reversible inactivation of the hippocampal mossy fiber synapses in mice impairs spatial learning, but neither consolidation nor memory retrieval, in the Morris navigation task. Neurobiol Learn Mem 73:243-257. CrossRef Medline

Lee I, Kesner RP (2004) Differential contributions of dorsal hippocampal subregions to memory acquisition and retrieval in contextual fearconditioning. Hippocampus 14:301-310. CrossRef Medline

Leutgeb JK, Leutgeb S, Moser MB, Moser EI (2007) Pattern separation in the dentate gyrus and CA3 of the hippocampus. Science 315:961-966. CrossRef Medline

Lissek S, Rabin S, Heller RE, Lukenbaugh D, Geraci M, Pine DS, Grillon C (2010) Overgeneralization of conditioned fear as a pathogenic marker of panic disorder. Am J Psychiatry 167:47-55. CrossRef Medline

Liu X, Ramirez S, Pang PT, Puryear CB, Govindarajan A, Deisseroth K, Tonegawa S (2012) Optogenetic stimulation of a hippocampal engram activates fear memory recall. Nature 484:381-385. CrossRef Medline

Madroñal N, Delgado-García JM, Fernández-Guizán A, Chatterjee J, Köhn M, Mattucci C, Jain A, Tsetsenis T, Illarionova A, Grinevich V, Gross CT, Gruart A (2016) Rapid erasure of hippocampal memory following inhibition of dentate gyrus granule cells. Nat Commun 7:10923. CrossRef Medline

Maren S, Phan KL, Liberzon I (2013) The contextual brain: implications for fear conditioning, extinction and psychopathology. Nat Rev Neurosci 14:417-428. CrossRef Medline

McHugh TJ, Jones MW, Quinn JJ, Balthasar N, Coppari R, Elmquist JK, Lowell BB, Fanselow MS, Wilson MA, Tonegawa S (2007) Dentate gyrus NMDA receptors mediate rapid pattern separation in the hippocampal network. Science 317:94-99. CrossRef Medline

Milad MR, Quirk GJ (2012) Fear extinction as a model for translational neuroscience: ten years of progress. Annu Rev Psychol 63:129-151. CrossRef Medline

Mineka S, Zinbarg R (2006) A contemporary learning theory perspective on the etiology of anxiety disorders: it's not what you thought it was. Am Psychol 61:10-26. CrossRef Medline

Myers KM, Davis M (2002) Behavioral and neural analysis of extinction. Neuron 36:567-584. CrossRef Medline

Nakashiba T, Cushman JD, Pelkey KA, Renaudineau S, Buhl DL, McHugh TJ, Rodriguez Barrera V, Chittajallu R, Iwamoto KS, McBain CJ, Fanselow MS, Tonegawa S (2012) Young dentate granule cells mediate pattern separation, whereas old granule cells facilitate pattern completion. Cell 149:188-201. CrossRef Medline

O'Reilly RC, McClelland JL (1994) Hippocampal conjunctive encoding, storage, and recall: avoiding a trade-off. Hippocampus 4:661-682. CrossRef Medline

Pan YW, Chan GC, Kuo CT, Storm DR, Xia Z (2012) Inhibition of adult neurogenesis by inducible and targeted deletion of ERK5 mitogenactivated protein kinase specifically in adult neurogenic regions impairs contextual fear extinction and remote fear memory. J Neurosci 32:64446455. CrossRef Medline

Pavlov IP (1927) Conditioned reflexes: an investigation of the physiological activity of the cerebral cortex. London: H. Milford.

Plendl W, Wotjak CT (2010) Dissociation of within- and between-session extinction of conditioned fear. J Neurosci 30:4990-4998. CrossRef Medline

Quirk GJ, Mueller D (2008) Neural mechanisms of extinction learning and retrieval. Neuropsychopharmacology 33:56-72. CrossRef Medline

Ramirez S, Liu X, Lin PA, Suh J, Pignatelli M, Redondo RL, Ryan TJ, Tonegawa S (2013) Creating a false memory in the hippocampus. Science 341:387-391. CrossRef Medline

Redondo RL, Kim J, Arons AL, Ramirez S, Liu X, Tonegawa S (2014) Bidirectional switch of the valence associated with a hippocampal contextual memory engram. Nature 513:426-430. CrossRef Medline

Rescorla RA, Heth CD (1975) Reinstatement of fear to an extinguished conditioned stimulus. J Exp Psychol Anim Behav Process 1:88-96. CrossRef Medline

Rolls ET (1996) A theory of hippocampal function in memory. Hippocampus 6:601-620. CrossRef Medline

Rolls ET, Kesner RP (2006) A computational theory of hippocampal function, and empirical tests of the theory. Prog Neurobiol 79:1-48. CrossRef Medline

Royer S, Zemelman BV, Losonczy A, Kim J, Chance F, Magee JC, Buzsáki G (2012) Control of timing, rate and bursts of hippocampal place cells by dendritic and somatic inhibition. Nat Neurosci 15:769-775. CrossRef Medline

Rudy JW, Huff NC, Matus-Amat P (2004) Understanding contextual fear conditioning: insights from a two-process model. Neurosci Biobehav Rev 28:675-685. CrossRef Medline

Ryan TJ, Roy DS, Pignatelli M, Arons A, Tonegawa S (2015) Memory. Engram cells retain memory under retrograde amnesia. Science 348:10071013. CrossRef Medline

Sahay A, Scobie KN, Hill AS, O'Carroll CM, Kheirbek MA, Burghardt NS, Fenton AA, Dranovsky A, Hen R (2011) Increasing adult hippocampal neurogenesis is sufficient to improve pattern separation. Nature 472:466470. CrossRef Medline

Samuels BA, Anacker C, Hu A, Levinstein MR, Pickenhagen A, Tsetsenis T, Madroñal N, Donaldson ZR, Drew LJ, Dranovsky A, Gross CT, Tanaka KF, Hen R (2015) 5-HT1A receptors on mature dentate gyrus granule cells are critical for the antidepressant response. Nat Neurosci 18:16061616. CrossRef Medline

Santarelli L, Saxe M, Gross C, Surget A, Battaglia F, Dulawa S, Weisstaub N, Lee J, Duman R, Arancio O, Belzung C, Hen R (2003) Requirement of hippocampal neurogenesis for the behavioral effects of antidepressants. Science 301:805-809. CrossRef Medline

Schoch S, Cibelli G, Thiel G (1996) Neuron-specific gene expression of syn- 
apsin I. Major role of a negative regulatory mechanism. J Biol Chem 271:3317-3323. CrossRef Medline

Seo D-O, Carillo MA, Chih-Hsiung Lim S, Tanaka KF, Drew MR (2015) Adult hippocampal neurogenesis modulates fear learning through associative and nonassociative mechanisms. J Neurosci 35:11330-11345. CrossRef Medline

Snyder JS, Soumier A, Brewer M, Pickel J, Cameron HA (2011) Adult hippocampal neurogenesis buffers stress responses and depressive behaviour. Nature 476:458-461. CrossRef Medline

Sparta DR, Stamatakis AM, Phillips JL, Hovelsø N, van Zessen R, Stuber GD (2011) Construction of implantable optical fibers for long-term optogenetic manipulation of neural circuits. Nat Protoc 7:12-23. CrossRef Medline

Stefanelli T, Bertollini C, Lüscher C, Muller D, Mendez P (2016) Hippocampal somatostatin interneurons control the size of neuronal memory ensembles. Neuron 89:1074-1085. CrossRef Medline

Swan AA, Clutton JE, Chary PK, Cook SG, Liu GG, Drew MR (2014) Characterization of the role of adult neurogenesis in touch-screen discrimination learning. Hippocampus 24:1581-1591. CrossRef Medline

Tanaka KZ, Pevzner A, Hamidi AB, Nakazawa Y, Graham J, Wiltgen BJ
(2014) Cortical representations are reinstated by the hippocampus during memory retrieval. Neuron 84:347-354. CrossRef Medline

Treves A, Rolls ET (1994) Computational analysis of the role of the hippocampus in memory. Hippocampus 4:374-391. CrossRef Medline

Tronson NC, Schrick C, Guzman YF, Huh KH, Srivastava DP, Penzes P, Guedea AL, Gao C, Radulovic J (2009) Segregated populations of hippocampal principal CA1 neurons mediating conditioning and extinction of contextual fear. J Neurosci 29:3387-3394. CrossRef Medline

Tronson NC, Corcoran KA, Jovasevic V, Radulovic J (2012) Fear conditioning and extinction: emotional states encoded by distinct signaling pathways. Trends Neurosci 35:145-155. CrossRef Medline

Trouche S, Perestenko PV, van de Ven GM, Bratley CT, McNamara CG, Campo-Urriza N, Black SL, Reijmers LG, Dupret D (2016) Recoding a cocaine-place memory engram to a neutral engram in the hippocampus. Nat Neurosci 19:564-567. CrossRef Medline

Wang ME, Yuan RK, Keinath AT, Ramos Álvarez MM, Muzzio IA (2015) Extinction of learned fear induces hippocampal place cell remapping. J Neurosci 35:9122-9136. CrossRef Medline

Wiltgen BJ, Sanders MJ, Anagnostaras SG, Sage JR, Fanselow MS (2006) Context fear learning in the absence of the hippocampus. J Neurosci 26:5484-5491. CrossRef Medline 